\title{
Jules Arthur Peter Paré
}

don't know if it is a conflict of interest for the Editor-in-Chief of a journal to write an obituary for his own father, but I'm not asking for permission. My father Jules Arthur (Peter) Paré MDCM BSc FACP, Professor Emeritus of Medicine McGill University (Montreal, Quebec) died on February 24, 2013, at 95 years of age after a long and full life. JAP, who was variously known as 'Uncle Pete', the 'Big Cheese' or 'Poppa', was a BIG man. He was big physically at 6 foot 4 inches; none of his seven sons or his nine grandsons and two great grandsons have yet to achieve his height. But Dad also had a big presence; he was big in action and impact. He influenced many people, family, friends, colleagues and students and, of course, the many people with respiratory and cardiovascular disease whom he helped.

After attending Collège Brébeuf and Loyola College (Toronto, Ontario), Dad graduated from McGill University as a physician in 1943. During the war, he joined the Air Force but the war ended before he was deployed overseas, and he

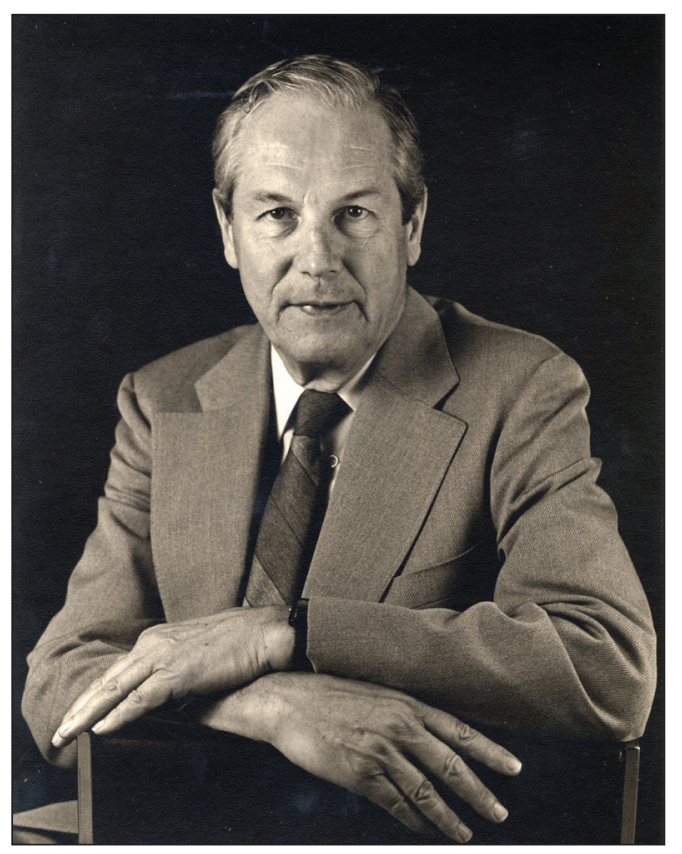

Dr Jules Arthur Paré
Son: Being any one of his nine children had its challenges...just getting his attention could be difficult. For some reason he always remembered my name...which was not the case for all of my siblings. However, Dad was the most amazing of fathers. Despite the fact that he and my Mother, Ann had nine children to care for, that he had a busy practice and many academic responsibilities, he was always there for us when needed. And with nine there were lots of needs!

Teacher: Having ended up as a lung specialist, it is natural that I look back to see if this career choice was actually one of free will... was I influenced by Dad? Of course I was, but I never felt any pressure from him, only encouragement.

Dad was one of my teachers during my training. I attended the now legendary 'Paré Rounds'. It was here that Dad's great friends Bob Fraser and Peter Macklem, along with pathologist Whitey Thurlbeck, provided a learning experience that I believe to be internationally unique.

During my training I used the text book resumed his training in internal medicine and respiratory medicine at McGill (1943 to 1948). In 1948/1949, he completed additional training as a postdoctoral fellow in chest medicine at Harvard University and the Massachusetts General Hospital (Boston, USA) before returning to McGill where he spent the duration of his career.

With his friend Bob Fraser, a pulmonary radiologist, he wrote four editions of the textbook Diagnosis of Diseases of the Chest. The text became internationally recognized and influenced generations of respiratory physicians, surgeons and radiologists. For the final two editions of the book, Dad and Bob recruited their sons, me and Rick Fraser - an outstanding pulmonary pathologist - as coauthors. For the fourth edition, Dad and Bob recommended Neil Coleman, an excellent clinician-teacher and Nestor Muller, a renowned lung radiologist, as coauthors. In 1975, Peter became a Professor of Medicine at McGill, and between 1975 and 1983, when he assumed Professor Emeritus status, he served as the Respiratory Division Head of the McGill teaching hospitals. In 2011, Peter received the Distinguished Achievement Award of the American Thoracic Society.

Dad was an educator. As one of his trainees, Jim Martin said, "He was a model for teaching with a humorous, gentle and always encouraging style". Another trainee, David Eidelman, recalled, "He never said you were wrong when you failed to get the correct diagnosis while viewing the chest $\mathrm{x}$-ray. Dr Paré would simply say '... just step back a bit...' which gently implied that you had made the wrong diagnosis but gave you another chance. And while you still might not see it, after a while you would learn. And learn we did."

I think I have a unique perspective as the writer of Peter's obituary: as the eldest of his children, as his student and as his colleague.
Diagnosis of Diseases of the Chest coauthored by Dad and Bob Fraser as my bible, just as lung specialists and radiologists have done for decades. The tome was all about diagnosing lung disease, which is of course a key part of medicine. Dad was the master of diagnosis; he had an uncanny ability to listen to the patient's history, examine the blood test results, look at the $\mathrm{x}$-rays and come up with the right diagnosis. But this is just the first step. The next step is deciding what to do, what treatment, drug or surgery to recommend. This skill, called 'clinical judgment', is at least as important as the diagnosis and Dad excelled at it. Clinical judgment is where medicine is more art than science, and teaching by example is crucial. Generations of lung specialists at McGill University learned how to make the best clinical decisions from Dad.

Colleague: As fellow respirologists, we were able to discuss specific cases, advances in radiology or the practice of respiratory medicine. He could appreciate my research papers and make suggestions for future study; this is a privilege not many sons or respirologists can claim; he taught me a lot. Writing the 3rd and 4th edition of the book with Bob Fraser, Neil Coleman and Nestor Muller was a highlight of my career, although a lot of work! The book stands as a monument to two outstanding teachers Peter Paré and Bob Fraser.

Dad was the consummate clinician-teacher. Through his teaching and his books he influenced two generations of lung specialists at McGill, and these, in turn, shaped respiratory medicine across Canada and North America.

Peter Paré MD

Editor-in-Chief, Canadian Respiratory Journal 


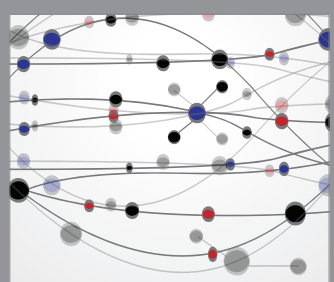

The Scientific World Journal
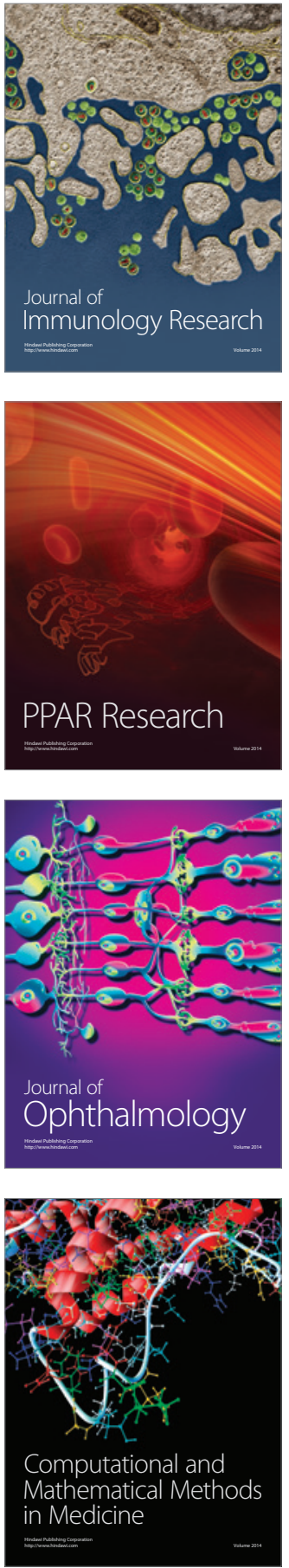

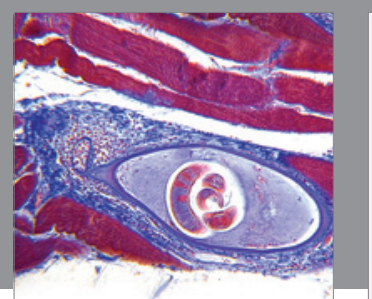

Gastroenterology Research and Practice

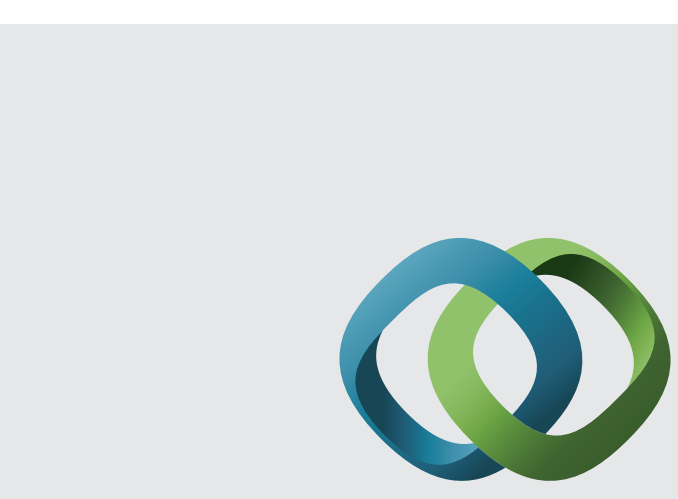

\section{Hindawi}

Submit your manuscripts at

http://www.hindawi.com
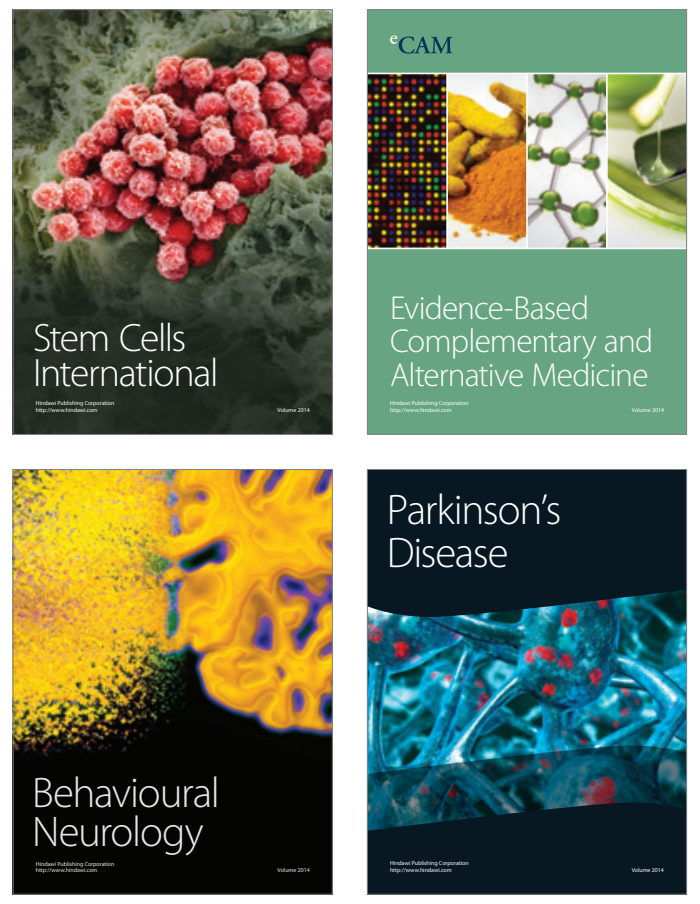
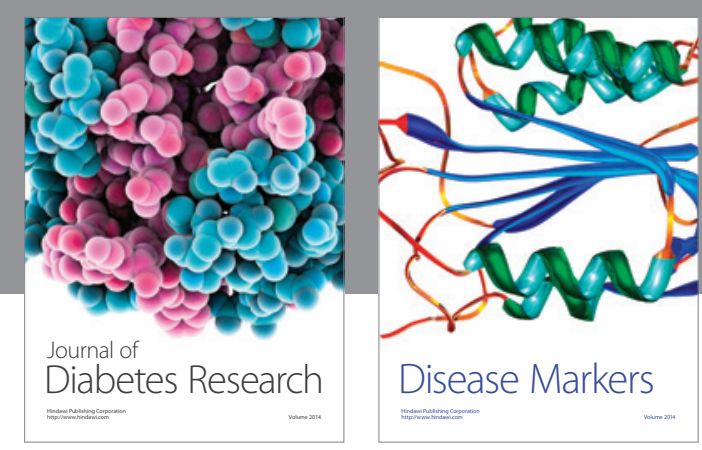

Disease Markers
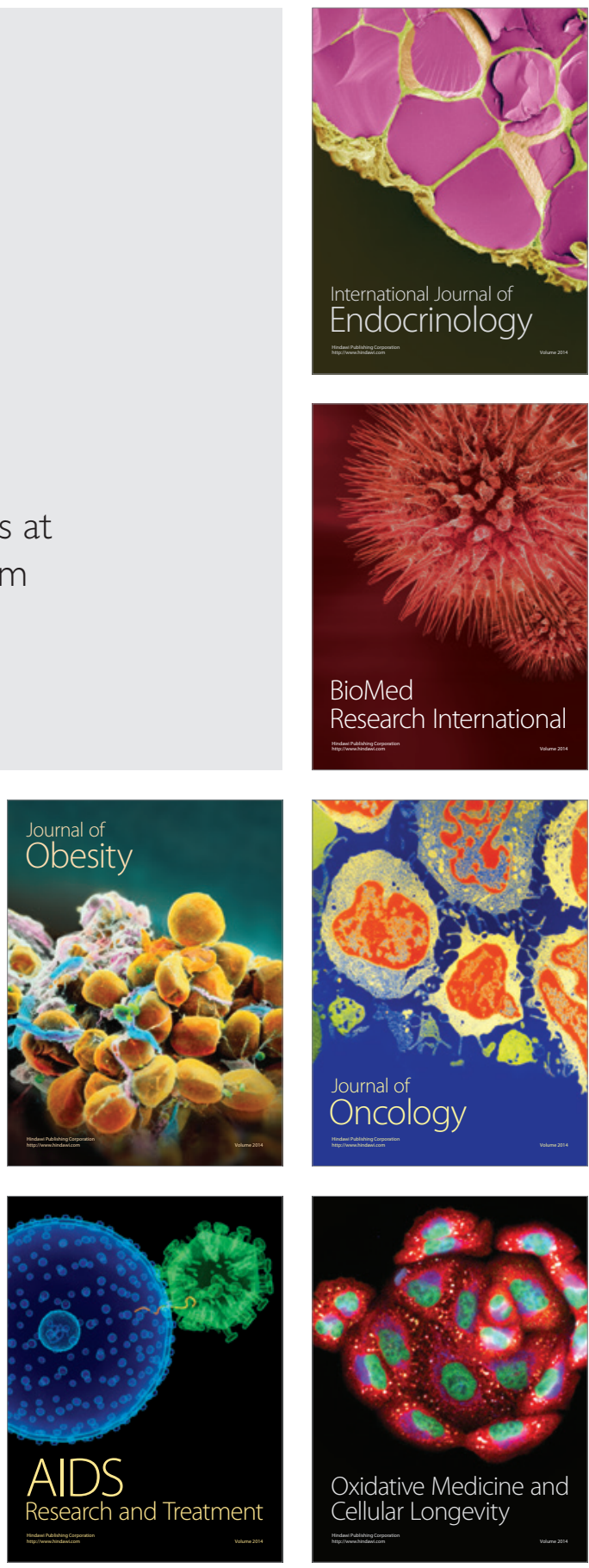